\title{
EDITORIAL
}

\section{Reforma a la salud: El camino por recorrer ${ }^{1}$}

Los distintos actores involucrados en la reforma del sector salud coinciden, en términos generales, en que el conjunto de medidas contenidas en las leyes que fueron tramitadas -no solo el Augeapuntaba a resolver los principales problemas de salud, individuales y colectivos. Al respecto, como es sabido, la Escuela de Salud Pública se pronunció en su momento expresando sus inquietudes e interrogantes mediante artículos publicados en esta revista.

Hoy es necesario saber cómo las razones que tuvimos para reformar la salud en Chile se han ido cumpliendo o no con el devenir de la Reforma. En otras palabras ¿Se han cumplido los objetivos propuestos y en qué grado?, y de manera especial ¿Están resueltos los vacíos de cobertura que generaban sorpresas a los beneficiarios en los planes de las Isapre? ¿Han sido reducidas o eliminadas las listas de espera, expresión de los mismos vacíos de cobertura en el subsistema público? ¿Se han eliminado los casos de compatriotas que enfrentados a un problema de salud caían en insolvencia financiera? En definitiva ¿Fueron eficaces los caminos elegidos para reformar? Desgraciadamente, no lo sabemos, porque no se cuenta con evaluaciones apropiadas y desconocemos los mecanismos que la propia reforma debió haber previsto para contar con dicha evaluación.

La falta de evaluación, cabe reconocer, representa hoy en Chile una carencia más amplia y universal en la gestión pública. Sabemos que es un mecanismo indispensable para impulsar y catalizar apropiadamente los programas de desarrollo como país y, por otra parte, es el mínimo que merece nuestra ciudadanía, que por intermedio de los gobernantes elige a los gestores públicos.

Al mirar esta Reforma, parece que sus alcances estratégicos podrían estar limitados a una cuestión principalmente asistencial, que surge de la sola idea de resolver problemas o patologías ya declaradas. Sin embargo, asalta la convicción de que existe una enorme cartera de posibles intervenciones que permitirían anticiparse a la aparición de estos daños, pero que no surgen de la demanda espontánea de la población. Ellas requieren una aproximación mucho más proactiva y con una orientación a la prevención, que debe emanar de la autoridad sanitaria.

Esto, por cierto, supone ofrecer resistencia a los intereses inmediatos del "complejo médico-industrial", el cual siempre despliega su atractiva oferta, al igual que transformar el paradigma vigente, lo que ciertamente no es fácil. Probablemente no lo ha sido en ninguna parte del mundo ni en ninguna época. Esto es lo que, por otra parte, explica la irrelevancia que la Reforma asignó originalmente al nivel primario de atención, el que ahora está recibiendo la debida prioridad.

En segundo lugar, la complejidad de un diseño de corte "enciclopedista" hizo prever serios problemas al momento de su implementación. Ello era previsible sólo por el hecho de tener entre manos una transformación que no respeta en lo sustantivo la manera en que tradicionalmente se ha desempeñado el sistema de salud en Chile, lo que representa una inconsistencia con la tradición y nos sitúa ad-portas de la necesidad de introducir un cambio cultural de gran envergadura, que podría estar justificado, pero que se enfrenta sin que se hayan previsto los mecanismos apropiados para producirlo. Y no es que no exista evidencia científica al respecto. Así las cosas, el sistema tenderá tarde o temprano a volver a su viejo cauce.

Resumen de la exposición realizada en el $4^{\circ}$ seminario internacional "Fuentes y organización del financiamiento en salud", organizado por FONASA. 
Hoy sabemos que existen problemas de implementación. Sin embargo, necesitamos información y evidencia que no provenga de la prensa para poder afirmarlo con tranquilidad y, en consecuencia, poder contribuir a resolverlos. Lamentablemente, la carencia de información confiable es precisamente uno de los grandes problemas de la implementación, porque esta es una Reforma que se diseñó sobre el supuesto de que todo se podía medir.

Sabemos también que en materia de política pública las separaciones tajantes entre diseño e implementación sobresimplifican la realidad, que por cierto es compleja. La idea de "formación de políticas" hace mucho más sentido, pues representa un continuo donde diseño e implementación se amalgaman en un proceso de suyo complejo, en que la reforma se va abriendo paso en medio de los intereses de los stakeholders. La realidad es así. Avanzamos tres o cuatro pasos para luego retroceder dos. Tomamos un curso de acción, pero a lo mejor luego, de cara a la realidad, habrá que tomar el curso alternativo. Es la evaluación sistemática, el apropiado monitoreo del proceso de cambio el que alimenta la formación de las políticas públicas. Sin esto, es sólo ensayo y error.

Sin embargo, esta manera de mirar los procesos de los "asuntos públicos" no nos limita al momento de identificar algunos problemas que hoy podrían asignarse preferentemente al diseño.

Entre ellos, podemos afirmar que no existe verdadera armonía entre la lógica de los derechos ciudadanos y la lógica contenida en los procesos de priorización basados en la carga de enfermedad. La primera no tolera la exclusión o la discriminación y la segunda sí lo hace, muchas veces explícitamente y muy justificadamente, con el argumento de los recursos escasos. Pero estas lógicas no son lo mismo y surgirán problemas a partir de ello. Como por ejemplo, minorías portadoras de una enfermedad que representa pocos años de vida saludables perdidos o quizás el estado de salud de los viejos, castigados al momento del cálculo de los AVISA, en su momento demandarán por sus derechos.

En segundo lugar, la priorización a partir de enfermedades, siguiendo las recomendaciones de los estudios de carga de enfermedad, son una cosa muy distinta a lo que se desprende finalmente del método utilizado para definir las guías y protocolos. En este último caso, lo relevante es la costoefectividad de las intervenciones y, en esa ecuación la elasticidad de la demanda por las mismas, que muchas veces hará de los costos una cuestión difícil de predecir.

En tercer término, hay una evidente confusión entre las ideas de autorización sanitaria y de acreditación. Es probable que esta distinción acomode en principio al administrador del problema, pero nos parece que quien no acredite no puede estar a la vez autorizado para funcionar. De lo contrario, se abre un flanco muy difícil de administrar en el terreno de la responsabilidad civil, en particular en un ambiente en que se pone el acento en los derechos ciudadanos.

Por otra parte, el grado de involucramiento de los gestores clínicos en la Reforma -los jefes de servicios clínicos de los hospitales públicos-, que son quienes finalmente gobiernan los procesos productivos y determinan qué y cuánto hacer, ha sido claramente insuficiente. Sin embargo, esta parte de la Reforma se reduce a un problema de gestión clínica a la hora de dar cuenta de las garantías. Pero ¿Cómo se modifica la conducta de los prestadores en una Reforma? Si a ello se agrega las limitaciones administrativas que los hospitales tienen para hacer su tarea, aun en el escenario de la autogestión, esto compromete severamente la posibilidad de cumplir con la oportunidad en la atención que promete el Auge.

Por último, parece atractiva y necesaria la idea de distinguir funciones en el sector, pero la implementación de la autoridad sanitaria representada por las Seremis, se realizó sin un debido cuidado por el fortalecimiento de las competencias necesarias para hacer una gestión de salud pública eficiente. Esto es un tema pendiente. 
El cierre del compromiso de la Reforma con la ciudadanía debe ser saldado. No es posible hacerlo, sin embargo, sin una debida y oportuna evaluación. Sus objetivos fueron explicitados y es posible hacer un esfuerzo por conocer de un modo objetivo y confiable el grado en que éstos se han venido cumpliendo.

El mundo académico brinda el espacio y competencias que una evaluación requiere para cumplir con los requisitos principales que debieran importar a la ciudadanía. Esto es indispensable para avanzar, retroalimentar y corregir. Del mismo modo, el espacio académico es el espacio para la investigación. Decenas de problemas se hacen evidentes en este proceso de cambio que se vive en el sector, y muchos de ellos demandan evidencia científica o desarrollo de competencias específicas para su solución.

Giorgio Solimano

Director 